\title{
Cost-effectiveness of a complex intervention to reduce children's exposure to second-hand smoke in the home
}

Charlotte Renwick', Qi Wu ${ }^{1 *} \mathbb{D}$, Magdalena Opazo Breton², Rebecca Thorley ${ }^{3}$, John Britton ${ }^{4}$, Sarah Lewis $^{4}$, Elena Ratschen ${ }^{1}$ and Steve Parrott ${ }^{5}$

\begin{abstract}
Background: Second-hand smoke (SHS) causes numerous health problems in children such as asthma, respiratory tract infections and sudden infant death syndrome. The home is the main source of exposure to SHS for children, particularly for young children. We estimated the cost-effectiveness of a complex intervention designed to reduce SHS exposure of children whose primary caregiver feels unable or unwilling to quit smoking.

Methods: A cost-effectiveness analysis was carried out alongside an open-label, parallel, randomised controlled trial in deprived communities in Nottingham, England. A complex intervention combining behavioural support, nicotine replacement therapy and personalised feedback on home air quality was compared with usual care. A total number of 205 households were recruited, where the main caregivers were aged 18 and over, with a child aged under five years living in their household reporting smoking inside their home. Analyses for this study were undertaken from the National Health Service/Personal Social Services perspective. All costs were estimated in UK pounds (£) at 2013/ 14 prices. The primary outcome was the incremental cost-effectiveness of change in air quality in the home, measured as average $16-24 \mathrm{~h}$ levels of particulate matter of $\leq 2.5 \mu \mathrm{m}$ diameter $\left(\mathrm{PM}_{2.5}\right)$, between baseline and 12 weeks. Secondary outcomes included incremental cost per quitter, quit attempts and cigarette consumption in the home. A non-parametric bootstrap re-sampling technique was employed to explore uncertainty around the calculated incremental cost-effectiveness ratios.
\end{abstract}

Results: The complex intervention achieved reduced $\mathrm{PM}_{2.5}$ by $21.6 \mu \mathrm{g} / \mathrm{m}^{3}$ (95\% Cl: 5.4 to 37.9), with an incremental cost of $£ 283$ (95\% Cl: $£ 254-£ 313$ ), relative to usual care. The incremental cost-effectiveness ratio was $£ 131$ (bootstrapped 95\% Cl: $£ 72-£ 467$ ) per additional $10 \mu \mathrm{g} / \mathrm{m}^{3}$ reduction in $\mathrm{PM}_{2.5}$, or $£ 71$ (bootstrapped 95\% Cl: - $£ 57-$ $£ 309)$ per additional quitter.

Conclusions: This trial targeted a socio-economically disadvantaged population that has been neglected within the literature. The complex intervention was more costly but more effective in reducing PM2.5 compared with the usual care. It offers huge potential to reduce children's' tobacco-related harm by reducing exposure to SHS in the home. The intervention is considered cost-effective if the decision maker is willing to pay $£ 131$ per additional 10 $\mathrm{\mu g} /$ $\mathrm{m}^{3}$ of $\mathrm{PM}_{2.5}$ reduction.

Trial registration: The Smoke Free Homes trial was registered with isrctn.com on 29 January 2013 with the identifier ISRCTN81701383.

Keywords: Second-hand smoke, Smoking cessation, Passive smoking, Environmental tobacco smoke pollution, Cost-effectiveness analysis

\footnotetext{
* Correspondence: qi.wu@york.ac.uk

${ }^{1}$ Department of Health Sciences, University of York, ARRC, Area 4, Heslington,

York Y010 5DD, UK

Full list of author information is available at the end of the article
}

(c) The Author(s). 2018 Open Access This article is distributed under the terms of the Creative Commons Attribution 4.0 International License (http://creativecommons.org/licenses/by/4.0/), which permits unrestricted use, distribution, and reproduction in any medium, provided you give appropriate credit to the original author(s) and the source, provide a link to the Creative Commons license, and indicate if changes were made. The Creative Commons Public Domain Dedication waiver (http://creativecommons.org/publicdomain/zero/1.0/) applies to the data made available in this article, unless otherwise stated. 


\section{Background}

The harmful health effects of second-hand smoke (SHS), also known as environmental tobacco smoke, on children are well established [1,2]. SHS exposure in children is associated with higher risks of various diseases, including asthma and wheeze [3], respiratory tract infections [4], middle ear disease [5], and even sudden infant death syndrome [2]. The home is the main source of exposure to SHS for children, particularly for young children [6]. It is estimated that around 2 million children are regularly exposed to SHS in the home in the UK [7]. As smoking prevalence is generally higher among caregivers from socio-economically disadvantaged groups [8], children from those households face higher exposure to SHS and increased risk of developing SHS-related diseases [9], which can lead to future health inequalities through intergenerational perpetuation of tobacco dependence and harm [10]. In the UK, SHS smoke in children accounts for 165,000 new episodes of diseases, at an estimated cost of about $£ 23.3$ million each year [2]. The long-term costs of treating smoking-caused diseases for smokers who take up smoking as a consequence of exposure to SHS has been estimated at $£ 5.7$ million per year, plus an additional annual $£ 5.6$ million in lost productivity [2]. All these costs are potentially avoidable [2]. In addition to improved child health, reducing air pollution in the home will also benefit other family members.

Smoking cessation programmes are one of the most cost-effective healthcare interventions available in the UK [11-13]. The majority of smoking cessation interventions are focused on people who are motivated to quit; less attention has been paid to those unwilling to quit. This population, although unwilling to quit, may be amenable to stop smoking within the home, reducing the adverse effects on their children through SHS exposure [14]. Despite the rapidly declining smoking prevalence in the UK, it is important to engage smokers from disadvantaged groups and smokers unwilling to quit, who have yet to respond to existing stimuli to quit [15]. A meta-analysis by Rosen et al. [16] evaluated seven studies (six in the US and one in Scotland) aimed at reducing SHS exposure. The results suggested that interventions aimed at reducing SHS exposure, with the primary outcome as air pollution, were effective but limited. However, the cost-effectiveness of these interventions was unclear since no analysis of cost-effectiveness was conducted and no costs of intervention reported.

In this study, we report a cost-effectiveness analysis (CEA) conducted in the context of a randomised controlled trial (RCT) comparing a complex intervention with usual care in reducing children's SHS exposure in the home [17]. The intervention consisted of both pharmacological and behavioural support as well as a personalised indoor air quality feedback. Our objectives were to compare the costs associated with the complex intervention strategies and the usual care, estimate the effectiveness measured using $\mathrm{PM}_{2.5}$ levels, consumption of cigarettes in the home, quit attempts and quit rates and assess the cost-effectiveness of the complex intervention compared with the usual care.

\section{Methods}

\section{The smoke free homes trial}

The trial for which the economic evaluation was conducted was the Smoke Free Homes Trial (Trial registration: ISRCTN81701383), as reported in detail elsewhere [17]. In brief, the trial was an open-label, parallel, RCT based in deprived communities in Nottingham City and County in England. Caregivers aged 18 and over, with a child aged under five living in their household, reported smoking tobacco inside their home and were not willing to quit were recruited and randomised to receive either the complex intervention or usual care. Participants were recruited from 81 English 'Sure Start' Children's Centres across Nottinghamshire. A researcher and a smoke-free homes advisor (SFHA) collected data during home visits at baseline, seven and 12 weeks.

The complex intervention had several components, including behavioural support from a SFHA on how to create a SFH, feedback on the air quality measured in the home, and nicotine replacement therapy (NRT) for temporary abstinence or for reducing number of cigarettes smoked in the home. Participants in the control group received the usual care: a 'SFH resource pack' developed by the local Stop Smoking Service. Full details of the study design and intervention have been described in a companion paper presenting the clinical results of the Smoke Free Homes trial [17]. This paper presents a CEA carried out alongside the Smoke Free Homes Trial to assess the value for money of the intervention.

\section{Resource use}

A micro-costing exercise was conducted following the methods of technology appraisal recommended by the National Institute for Health and Care Excellence (NICE) [18]. The main costing component for the alternative strategies was the costs of inputs for the interventions. No wider health care resource use was collected and all trial-related research costs were excluded. Costs for the intervention group were based on three components: (1) up to four one-hour sessions of behavioural support in the home from a SFHA and a minimum of two proactive phone calls or SMS support; (2) NRT and (3) feedback on the air quality $\left(\mathrm{PM}_{2.5}\right)$ of the main living area at baseline, seven and 12 weeks, measured using the Sidepak Aerosol Monitor AM510 (TSI Instruments Ltd., High Wycombe, UK) with the Trakpro software already installed. Intervention cost for the usual care 
group was based on one face-to-face home visit and a resource pack provided by Nottingham Smoke-free homes. Intervention costs, therefore, included the staff cost of the SFHAs along with the relevant travel and telephone expenses, the cost of NRT and the air monitors.

The household cost for contact with the SFHAs was calculated from the treatment log, which recorded the number of visits per household and the length of appointment for baseline, 7 weeks and 12 weeks. Where an appointment time was not given, it was calculated using the estimates of 10 min for graphical feedback and $10 \mathrm{~min}$ for behavioural support. For the intervention group, the 24-h visit was estimated at $20 \mathrm{~min}$ and the week three visit at $10 \mathrm{~min}$. The advisor wage rate was calculated from the mean of a band 5 and 6 smoking advisor wage [19-21]. Travel time and distance from the hospital were recorded in the treatment log. A return trip was calculated based on the mileage, travel time and advisor wage rate.

Within the treatment log telephone calls were recorded at $10 \mathrm{~min}$ per call. Before each visit an additional courtesy call was made to the caregiver. NRT dispensed per person was recorded within the treatment log and costed according to the quantity given per household.

The cost of the air monitor was calculated for 1 year of its 10 life-years (estimated by the manufacturer) and then a cost per use was derived by dividing the annual cost by the number of uses, based on the assumption that the device could be used every other day. Included in the annual cost were the yearly calibration and other fixed costs such as the flow meter. Graphical feedback was costed as $10 \mathrm{~min}$ of the appointment time with the associated printing costs.

\section{Valuation of costs}

All resource use was valued in monetary terms, and unit costs were reported in pounds sterling for the financial year 2013/14. All costs were inflated to 2013/14 prices levels where necessary, using the Hospital and Community Health Services pay and price inflation index [22]. The follow-up for the analysis was 12 weeks from randomisation, so no discounting was needed. Table 1 reports the unit costs used in order to cost the intervention. For the support pack, Public Health England provided information on the Smokefree Homes and

Table 1 Unit costs and their sources

\begin{tabular}{|c|c|c|}
\hline Resource & Unit cost & Sources \\
\hline Smoking advisor & $£ 31 / h$ & Smoking Cessation Services (NICE) [19] \\
\hline Travel & $£ 0.45 /$ mile & Estimated from Smoke Free Homes trial \\
\hline Telephone call & $£ 0.63 / \mathrm{min}$ & Estimated from Smoke Free Homes trial \\
\hline SMS & $£ 0.04 /$ text & Estimated from Smoke Free Homes trial \\
\hline Air monitor & $£ 0.60 /$ use & Calculated using manufacturer's lifetime estimates \\
\hline Support pack & $£ 1.45 /$ pack & Public Health England (PHE) [23] \\
\hline \multicolumn{3}{|l|}{ Medication (Quantity per pack) } \\
\hline 1.00 mg Nicorette Mouth Spray QuickMist - Double Pack (26) & $£ 19.43$ & Estimated from Smoke Free Homes trial \\
\hline 1.00 mg Nicorette Mouth Spray QuickMist - Individual Pack (13) & $£ 12.05$ & \\
\hline 2.00 mg Nicorette Lozenge Nicorette Cool (20) & $£ 4.25$ & \\
\hline 2.00 mg Nicorette Chewing Gum (30) & $£ 3.41$ & \\
\hline 2.00 mg Nicorette Chewing Gum Icy White (30) & $£ 3.58$ & \\
\hline 2.00 mg Nicorette Chewing Gum Icy White (105) & $£ 10.25$ & \\
\hline 4.00 mg Nicorette Chewing Gum Icy White (105) & $£ 12.05$ & \\
\hline 15.00 mg Nicorette Inhalator Inhalator (4) & $£ 4.35$ & \\
\hline 15.00 mg Nicorette Inhalator Inhalator (20) & $£ 15.40$ & \\
\hline 10.00 mg Nicorette Inhalator (starter pack) (6) & $£ 4.68$ & \\
\hline 10.00 mg Nicorette Inhalator (refill pack) (42) & $£ 15.39$ & \\
\hline 1.50 mg Niquitin CQ Lozenge Mint Mini Lozenge (20) & $£ 3.34$ & \\
\hline 1.50 mg Niquitin CQ Lozenge Mini Lozenge (60) & $£ 9.37$ & \\
\hline 4.00 mg Niquitin CQ Lozenge Mint Mini Lozenge (20) & $£ 3.18$ & \\
\hline 4.00 mg Niquitin CQ Lozenge Mini Lozenge (60) & $£ 9.37$ & \\
\hline 21.00 mg Nicotinell TTS 30 Patch (7) & $£ 8.73$ & \\
\hline 14.00 mg Nicotinell TTS 20 Patch (7) & $£ 8.24$ & \\
\hline
\end{tabular}


Cars kit, last distributed in 2012 and the unit cost of $£ 1.45$ was given, which was defined as covering production costs only (printing and postage but not fulfilment costs) [23].

\section{Outcome measures}

The primary outcome measure of the trial was the difference in average 16-24h $\mathrm{PM}_{2.5}$ between baseline and 12 weeks. Secondary outcome measures included number of quitters (those who self-reported they had "quit smoking altogether" at 12 weeks), number of quit attempts (lasting longer than 24-h) and difference in cigarette consumption (cigarettes smoked per day in the home) between baseline and 12 weeks.

\section{Cost-effectiveness analysis}

A CEA was undertaken to combine the costs of the trial intervention with $\mathrm{PM}_{2.5}$ level and the number of quitters. The primary analysis was conducted on an intentto-treat (ITT) basis, whereby all randomised households were included and analysed in the groups to which they were randomised. Following NICE guidelines, the analysis was conducted from the NHS/Personal Social Services perspective (including only costs that fall within the healthcare and social services system).

This article's companion paper used statistical models to adjust for baseline covariates; since there was little difference between those adjusted and those unadjusted, we utilised raw adjustments for our analysis [17]. This allowed us to present all results in the original units (PM2.5, quitters, quit attempts, consumption of cigarettes), which was more meaningful for an economic evaluation than log-transforming PM2.5. The results may differ slightly from the main paper because our multiple imputation model contained cost variables. The incremental cost-effectiveness ratio (ICER), in terms of cost per additional $10 \mu \mathrm{g} / \mathrm{m}^{3}$ reduction in $\mathrm{PM}_{2.5}$, was calculated using the mean difference in cost between two trial groups divided by the mean difference in effectiveness [24]. The ICER was calculated using $10 \mu \mathrm{g} / \mathrm{m}^{3}$ reduction, as this change in $\mathrm{PM}_{2.5}$ is utilised by the World Health Organisation (WHO) for mortality risk and therefore considered a meaningful reduction [25]. An additional ICER was calculated for cost per additional quitter. The ICER is calculated using the formula below; $\Delta$ represents difference, $E$ represents effects, $C$ represents the cost of the intervention, while subscripts 'I' and ' $U C$ ' refer to intervention and usual care, respectively [24].

$$
\operatorname{ICER}=\frac{\Delta \mathrm{C}}{\Delta \mathrm{E}}=\frac{\mathrm{C}_{\mathrm{I}}-\mathrm{C}_{\mathrm{UC}}}{\mathrm{E}_{\mathrm{I}}-\mathrm{E}_{\mathrm{UC}}}
$$

Missing data for outcomes $\left(16 \%\right.$ for $\left.\mathrm{PM}_{2.5}\right)$ costs $(7 \%)$ resulted from lost-to-follow-up were imputed using
Rubin's multiple imputation (MI) method [24, 26, 27]. As the data were not normally distributed, we used a non-parametric bootstrap re-sampling method to test the sensitivity of calculated ICERs [28-31]. 5000 estimates of mean costs and mean QALYs were generated for each intervention group and the results were then displayed graphically using a cost-effectiveness plane (CEP) to depict the uncertainty surrounding the mean estimates. To assess the uncertainty surrounding the ICER, bootstrapped 95\% confidence intervals (CIs) were generated.

In addition to the primary analysis based on the multiple imputed dataset, a sensitivity analysis was undertaken to repeat the CEA using the 172 out of 204 households who had complete data for the primary outcome and the 188 households who had complete data for number of quitters. All analyses were conducted with Stata version 14.0 and Excel (version 2013). Statistical significance was accepted at $P<0.05$ in each of the analyses.

\section{Results}

A total number of 205 households were recruited to the trial, but one withdrew from the intervention group, resulting in 204 households (102 in each group) included in the analysis. The majority of primary carers recruited to the trial were female, with just $9 \%$ male; the mean age was 28 , and $94 \%$ were white-British. Full details of trial participants and clinical outcomes are given elsewhere [17].

Table 2 presents a breakdown of the mean cost per household for each element of the intervention. The intervention group had a greater mean total intervention cost than the usual care group $(£ 328(\mathrm{SD}=£ 151)$ compared to $£ 45(\mathrm{SD}=£ 20)$ ). The biggest drivers in this difference were the use of NRT, travel cost and staff time also categorised as feedback time. Greater travel cost was attributable to the extra visits required for the intervention group, since the air monitor drop off/picks ups and the week seven and week 12 follow ups were not included in the costing of the usual care group, as these were considered research costs only (maximum number of visits costed for the intervention group was seven compared to one for the usual care group).

Table 3 reports the base-case results with a decrease of $22.1 \mu \mathrm{g} / \mathrm{m}^{3}$ in average $16-24 \mathrm{~h} \mathrm{PM}_{2.5}$ in the intervention group, compared to just $0.5 \mu \mathrm{g} / \mathrm{m}^{3}$ for the usual care group (this is also presented in Table 3 by $10 \mu \mathrm{g} / \mathrm{m}^{3}$ decrease, as was used for the ICER). This translated into a $41 \%$ mean reduction in the average $16-24-\mathrm{h}$ average $\mathrm{PM}_{2.5}$ between baseline and 12 weeks for the intervention group, compared with a $1 \%$ mean reduction in the usual care group. The quit rate was higher in the intervention group versus the usual care group $(8.0 \%$ compared to $4.3 \%, p$-value $=0.2614)$, but did not 
Table 2 Mean total cost per household

\begin{tabular}{llll}
\hline & Intervention $(S D)(n=102)$ & Usual Care (SD) $(n=102)$ & Difference $(95 \%$ Cl) \\
\hline Staff & $£ 29(£ 8)$ & $£ 11(£ 3)$ & $£ 18(£ 16$ to $£ 19)$ \\
Feedback & $£ 15(£ 2.70)$ & - & $£ 15(£ 14.65$ to $£ 15.70)$ \\
Telephone & $£ 10(£ 4)$ & $£ 0.10(£ 0)$ & $£ 10(£ 8.80$ to $£ 10.40)$ \\
Travel & $£ 216(£ 143)$ & $£ 32(£ 20)$ & $£ 184(£ 156$ to $£ 213)$ \\
NRT & $£ 56(£ 47)$ & - & $£ 56(£ 47$ to $£ 65)$ \\
Air monitor & $£ 1.68(£ 0.32)$ & - & $£ 1.68(£ 1.62$ to $£ 1.74)$ \\
Support pack & - & $£ 1.45(£ 0)$ & $£ 1.45(£ 1.45$ to $£ 1.45)$ \\
Total & $£ 328(£ 151)$ & $£ 45(£ 20)$ & $£ 283^{*}(£ 254$ to $£ 313)$ \\
\hline
\end{tabular}

*Statistically significant ( $p$-value $<0.001)$

reach statistical significance in either analysis. Table 4 shows the intervention group experienced a mean reduction of $11 \quad(\mathrm{SD}=10.7)$ cigarettes smoked in the home per day compared with the usual care's reduction of $4 \quad(\mathrm{SD}=10.8)$ fewer cigarettes smoked ( $p$-value $<0.001)$. The quit attempt rate was significantly higher in the intervention group $(29.4 \%$ compared to $8.6 \%, p$-value $<0.001$ ).

Tables 3 and 4 report the results of the complete case analysis, although there was little variation. The results only differed slightly between the base-case analysis and the complete case analysis with the average 16-24 $\mathrm{h} \mathrm{PM}_{2.5}$ results generally better for the intervention group in the base-case.

The primary outcome, average 16 to 24-h PM2.5, was selected for the CEA along with quitters. Table 3 presents the ICERs which combine the differential costs of the two groups with the differential outcome measures. The intervention group was more costly than the usual care group, but had a greater decrease in the PM2.5 level. This resulted in an ICER of $£ 131$ (bootstrapped 95\% CI: $£ 72-£ 467$ ) per additional
$10 \mu \mathrm{g} / \mathrm{m} 3$ reduction of 16 to 24-h PM2.5. Analyses of the quitters resulted in an ICER of $£ 71$ ( $-£ 57$ to $£ 309)$ per additional quitter. The uncertainty surrounding this ICER was reflected by the bootstrapped CIs for both analyses. The complete case analysis showed very similar results.

The bootstrapping results of the 5000 re-samples for each outcome were plotted on a CEP (Fig. 1), visually displaying any uncertainty surrounding the mean differences in costs and benefits between the intervention and usual care groups. Figure lashows this uncertainty for the primary outcome (PM2.5 difference). The majority of the plots fall in the south-east quadrant, this indicates although the intervention is always more costly, it is more likely to be effective at reducing $\mathrm{PM}_{2.5}$ levels, compared with usual care. The quit rate is more uncertain as shown by some of the plots falling in the south-east region of the CEP (Fig. 1b) therefore there is a lack of evidence to show the intervention was more effective at helping people to quit. This is unsurprising, as this was not the main aim of the trial.

Table 3 Results of $\mathrm{PM}_{2.5}$ and quit rate

\begin{tabular}{|c|c|c|c|c|c|c|c|c|}
\hline & \multicolumn{4}{|c|}{ Base-case analysis (with imputed data) } & \multicolumn{4}{|c|}{ Complete case analysis } \\
\hline & Intervention & Usual Care & Difference $(95 \% \mathrm{Cl})$ & $\begin{array}{l}P- \\
\text { value }\end{array}$ & Intervention & Usual care & Difference $(95 \% \mathrm{Cl})$ & $\begin{array}{l}P \text { - } \\
\text { value }\end{array}$ \\
\hline No. of households & $n=102$ & $n=102$ & $n=204$ & & $n=90$ & $n=82$ & $n=172$ & \\
\hline Cost (SD) & $£ 328(£ 151)$ & $£ 45(£ 20)$ & $£ 283$ (£254 to $£ 313)$ & $\begin{array}{l}< \\
0.001\end{array}$ & $£ 331(£ 149)$ & $£ 46(£ 21)$ & $£ 285$ (£252 to $£ 318)$ & $\begin{array}{l}< \\
0.001\end{array}$ \\
\hline Reduction in $\mathrm{PM}_{2.5}\left(\mathrm{ug} / \mathrm{m}^{3}\right)$ (SD) & $22.1(65.2)$ & $0.5(52.0)$ & $21.6(5.4$ to 37.9$)$ & 0.0096 & $24.0(58.9)$ & $0.9(52.4)$ & $23.2(6.3$ to 40.0$)$ & 0.007 \\
\hline $\begin{array}{l}\text { Reduction in } \mathrm{PM}_{2.5}\left(10 \mu \mathrm{g} / \mathrm{m}^{3}\right) \\
\text { (SD) }\end{array}$ & $2.21(6.52)$ & $0.05(5.20)$ & $2.16(0.54$ to 3.79$)$ & 0.0096 & $2.40(5.89)$ & $0.09(5.24)$ & 2.32 (0.63 to 4.0$)$ & 0.007 \\
\hline ICER (bootstrapped 95\% Cl) & \multicolumn{4}{|c|}{$£ 131$ (£72 to $£ 467)$} & \multicolumn{4}{|c|}{$£ 121(£ 70$ to $£ 471)$} \\
\hline No. of households & $n=102$ & $n=102$ & $n=204$ & & $n=95$ & $n=93$ & $n=188$ & \\
\hline Cost (SD) & $£ 328(£ 151)$ & $£ 45(£ 20)$ & $£ 283$ (£254 to $£ 313)$ & $\begin{array}{l}< \\
0.001\end{array}$ & $£ 331(£ 148)$ & $£ 44(£ 21)$ & $£ 286$ (£256 to $£ 317$ ) & $\begin{array}{l}< \\
0.001\end{array}$ \\
\hline Quit rate (\%)(SD) & $\begin{array}{l}8.0 \% \\
(27.0 \%)\end{array}$ & $\begin{array}{l}4.3 \% \\
(19.6 \%)\end{array}$ & $\begin{array}{l}3.7 \%(-2.8 \% \text { to } \\
10.2 \%)\end{array}$ & 0.2614 & $\begin{array}{l}8.4 \% \\
(27.9 \%)\end{array}$ & $\begin{array}{l}4.3 \% \\
(20.4 \%)\end{array}$ & $\begin{array}{l}4.1 \%(-2.9 \% \text { to } \\
11.2 \%)\end{array}$ & 0.248 \\
\hline ICER (bootstrapped 95\% Cl) & \multicolumn{4}{|c|}{$£ 71(-£ 57$ to $£ 309)$} & \multicolumn{4}{|c|}{$£ 72(-£ 22$ to $£ 313)$} \\
\hline
\end{tabular}


Table 4 Results of consumption of cigarettes in the home and quit attempts

\begin{tabular}{|c|c|c|c|c|c|c|c|c|}
\hline & \multicolumn{4}{|c|}{ Base-case analysis (with imputed data) } & \multicolumn{4}{|c|}{ Complete case analysis } \\
\hline & Intervention & $\begin{array}{l}\text { Usual } \\
\text { Care }\end{array}$ & $\begin{array}{l}\text { Difference }(95 \% \\
\mathrm{Cl})\end{array}$ & $\begin{array}{l}P \text { - } \\
\text { value }\end{array}$ & Intervention & $\begin{array}{l}\text { Usual } \\
\text { care }\end{array}$ & $\begin{array}{l}\text { Difference }(95 \% \\
\mathrm{Cl})\end{array}$ & $\begin{array}{l}P \text { - } \\
\text { value }\end{array}$ \\
\hline No. of households & $n=102$ & $n=102$ & $n=204$ & & $n=95$ & $n=93$ & $n=188$ & \\
\hline Cost (SD) & $£ 328(£ 151)$ & $£ 45(£ 20)$ & $\begin{array}{l}£ 283 \text { ( } £ 254 \text { to } \\
£ 313)\end{array}$ & $\begin{array}{l}< \\
0.001\end{array}$ & $£ 330(£ 148)$ & $£ 44(£ 21)$ & $\begin{array}{l}£ 286(£ 256 \text { to } \\
£ 317)\end{array}$ & $\begin{array}{l}< \\
0.001\end{array}$ \\
\hline $\begin{array}{l}\text { Reduction of consumption in the home (no. of } \\
\text { cigarettes per day) (SD) }\end{array}$ & $11(10.7)$ & $4(10.8)$ & $\begin{array}{l}7 \text { ( } 9.8 \text { to } 3.9 \text { to } \\
9.8)\end{array}$ & $\begin{array}{l}< \\
0.001\end{array}$ & $11(10.8)$ & $4(10.5)$ & 7.5 (4.4 to 10.6$)$ & $\begin{array}{l}< \\
0.001\end{array}$ \\
\hline No. of households & $n=102$ & $n=102$ & $n=204$ & & $n=93$ & $n=93$ & $n=186$ & \\
\hline Cost (SD) & $£ 328(£ 151)$ & $£ 45(£ 20)$ & $\begin{array}{l}£ 283(£ 254 \text { to } \\
£ 313)\end{array}$ & $\begin{array}{l}< \\
0.001\end{array}$ & $£ 331(£ 149)$ & $£ 44(£ 21)$ & $\begin{array}{l}£ 286(£ 256 \text { to } \\
£ 318))\end{array}$ & $\begin{array}{l}< \\
0.001\end{array}$ \\
\hline Quit attempt rate (\%)(SD) & $\begin{array}{l}29.4 \% \\
(43.6 \%)\end{array}$ & $\begin{array}{l}8.6 \% \\
(27.1 \%)\end{array}$ & $\begin{array}{l}20.7 \%(10.8 \% \text { to } \\
30.8 \%)\end{array}$ & $\begin{array}{l}< \\
0.001\end{array}$ & $29 \%(45.6 \%)$ & $\begin{array}{l}8.6 \% \\
(28.2 \%)\end{array}$ & $\begin{array}{l}20.4 \%(7.3 \% \text { to } \\
32.0 \%)\end{array}$ & $\begin{array}{l}< \\
0.001\end{array}$ \\
\hline
\end{tabular}

\section{Discussion}

To our knowledge, the present study is the first full economic evaluation alongside an RCT to assess the cost-effectiveness of a complex intervention designed to reduce children's exposure to SHS in the home. The study has shown the complex intervention significantly reduced SHS exposure in the home among families in which parents had expressed no interest in quitting smoking previously. Decision makers must be willing to pay $£ 131$ (bootstrapped 95\% CI: $£ 72-£ 467$ ) per additional $10 \mu \mathrm{g} / \mathrm{m}^{3}$ reduction of $\mathrm{PM}_{2.5}$ in order to reduce SHS in the home and limit harm to children. It was presented per additional $10 \mu \mathrm{g} / \mathrm{m}$ as this was seen as a meaningful reduction and is used by WHO when presenting mortality risk [25]. The results revealed the intervention was more costly (mean cost: $£ 328(\mathrm{SD}=£ 151)$ vs $£ 45(\mathrm{SD}=£ 20))$ than usual care, but produced better outcomes. Total mean costs were $£ 283$ (95\% CI: $£ 254$ to $£ 313$ ) higher in the intervention group, this was mostly attributable to the cost of travel with a mean difference of $£ 184$ (95\% CI: $£ 156$ to $£ 213$ ) and the cost of NRT with a mean difference of $£ 56$ (95\% CI: $£ 47$ to $£ 65$ ). Based on WHO recommendations, the safe level of $\mathrm{PM}_{2.5}$ is $<25 \mu \mathrm{g} / \mathrm{m}^{3}$ (24-h mean), however children are recognised as particularly vulnerable and there is no threshold below which adverse health effects do not occur [25, 32]. Neither the usual care nor intervention group met the WHO threshold at 12 weeks (usual care $=47 \mu \mathrm{g} / \mathrm{m}^{3}$, intervention $=32 \mu \mathrm{g} / \mathrm{m}^{3}$ ), but the intervention group did experience an overall reduction of $41 \%$ from baseline to 12 weeks.

The strength of the economic analysis has been impacted by a few limitations of the study. Firstly, wider health care resource use beyond the trial interventions was not collected and this plays an important role in the drive behind reducing SHS exposure. This cost dimension would have strengthened the economic analysis and brought it more in line with NICE guidelines. Secondly, the trial follow-up period was only 12 weeks, and it may not be long enough to capture the full impact of the intervention. Further research with longer-term follow-up is needed to explore any potential long-term benefits from the intervention.

This longer follow-up would also allow the use of the EQ-5D and the subsequent calculation of Quality Adjusted Life-Years (QALYs), a generic health measure [33-35]. QALYs can be used and easily compared across interventions with a willingness to pay thresholds range of $£ 20,000$ to $£ 30,000$ per additional QALY gained to decide cost-effectiveness [18]. However, QALYs can be insensitive to disease-specific conditions, in particular those concerning mental health [36]. Thirdly, no definitive conclusion about cost-effectiveness can be made due to the absence of decision-making thresholds for any of the outcomes collected alongside the trial.

These limitations aside, this trial targeted a socio-economically disadvantaged population that has been neglected within the literature. Previous research showed great success with sophisticated methods for interventions aimed at smokers who are serious about and willing to quit $[37,38]$. Despite the rapidly declining smoking prevalence, it is important to engage with smokers who have not yet responded to existing stimuli to quit [15]. New and innovative approaches are needed to target those who are not willing to quit, but may be willing to reduce consumption in the home, thereby limiting the impact of SHS on children. Our results showed a reduced number of cigarettes being smoked inside the home and lower $\mathrm{PM}_{2.5}$ level, indicating some success in the trial aims. Although not statistically significant, this intervention group had a $3.7 \%$ higher quit rate than usual care, suggesting even those who are seemingly not willing to quit are still able to and should not be ignored, but this result should be taken with caution due to the high level of uncertainty. The results showed a higher number of quit attempts in the intervention group (20.8\% higher quit attempt rate). Chaiton et al. [39] 

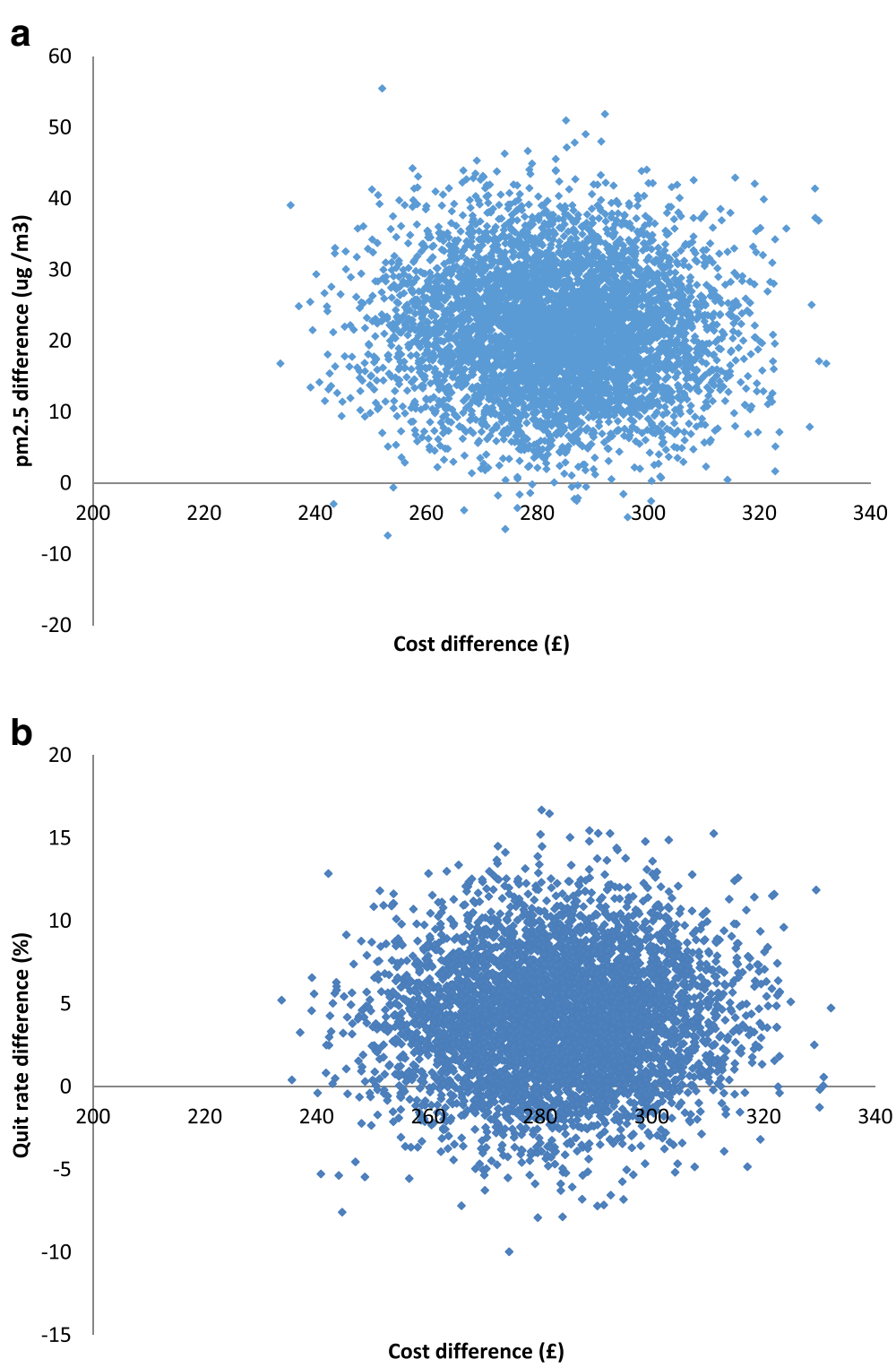

Fig. 1 The bootstrapping results of the 5000 re-samples for each outcome: a. PM2.5; b. Quit rate.

argue when taking into account those smokers who are less willing to quit, it may take 30 or more quit attempts before being successful. Therefore, these increased quit attempts may indicate a likelihood of longer term success.

More high quality research such as larger RCTs with longer follow-up periods, generic health outcome measures and collection of wider healthcare resource use is needed to explore the impact of complex interventions on reducing children's SHS exposure. Furthermore, studies exploring interventions that help those who are not willing to quit smoking are needed. These interventions may have short term objectives of reduced consumption, but with the potential of long term success of quitting.

\section{Conclusions}

This trial targeted a socio-economically disadvantaged population that has been neglected within the literature. The complex intervention was more costly but more effective in reducing PM2.5 compared with the usual care. It offers huge potential to reduce children's' tobacco-related harm by reducing exposure to secondhand tobacco smoke in the home. The intervention is considered cost-effective if the decision maker is willing to pay $£ 131$ per additional $10 \mu \mathrm{g} / \mathrm{m}^{3}$ of $\mathrm{PM}_{2.5}$ reduction.

\section{Abbreviations}

CEA: Cost-effectiveness analysis; CEP: Cost-effectiveness plane; Cl: Confidence interval; ICER: Incremental cost-effectiveness ratio; MI: Multiple imputation; 
NICE: National Institute for Health and Care Excellence; NRT: Nicotine replacement therapy; QALY: Quality adjusted life years; RCT: Randomised controlled trial; SFHA: Smoke free homes advisor; SHS: Second-hand smoke; WHO: World Health Organisation

\section{Acknowledgements}

We thank all caregivers and young people we recruited for taking part in this trial. We also thank the Children's Centre staff and health visitors who supported the trial across Nottinghamshire. We acknowledge the contribution of Juliette Cook for data collection. We also acknowledge the contributions of John Marsh, Alexandra Larwood, Jacqueline Purdy and Liza Aspell in Nottingham.

\section{Funding}

This trial was funded by the UK National Institute for Health Research (NIHR): RP-PG-0608-10020. The funding bodies played no role in the design of the study, nor in the collection, analysis, or interpretation of data.

\section{Availability of data and materials}

The datasets used and/or analysed during the current study are available from the corresponding author on reasonable request.

\section{Authors' contributions}

CR carried out the economic evaluation and write-up, QW contributed to the analysis and write-up, MOB was the statistician and contributed to the analysis, supervised by SL who provided strategic and statistical senior support, RT was the trial manager, responsible for the day-to-day management of the study, collected and cleaned data used in the economic analysis, JB and SL designed the programme of work which led to development and economic evaluation of the intervention, SP contributed to early evaluation design and provided economic senior support throughout, ER was the Chief Investigator responsible for the main trial paper, managing the team throughout. All authors contributed to the production of the paper. All authors read and approved the final manuscript.

\section{Ethics approval and consent to participate}

Ethics approved by National Research Ethics Service West Midlands, Solihull (REC, 25/09/2012, ref:: 12/WM/0286). Written informed consent was obtained by all human subjects before the research began.

\section{Consent for publication}

Not applicable

\section{Competing interests}

The authors declare that they have no competing interests.

\section{Publisher's Note}

Springer Nature remains neutral with regard to jurisdictional claims in published maps and institutional affiliations.

\section{Author details}

'Department of Health Sciences, University of York, ARRC, Area 4, Heslington, York YO10 5DD, UK. ${ }^{2}$ University of Nottingham, UK Centre for Tobacco and Alcohol Studies, Division of Epidemiology and Public Health, Clinical Sciences Building, City Hospital, Nottingham NG5 1PB, UK. ${ }^{3}$ University of Nottingham, Faculty of Medicine \& Health Sciences, Division of Epidemiology and Public Health, City Hospital, Nottingham NG5 1PB, UK. ${ }^{4}$ University of Nottingham, UK Centre for Tobacco Control Studies, Division of Epidemiology and Public Health, City Hospital, Nottingham NG5 1PB, UK. ${ }^{5}$ Department of Health Sciences, Seebohm Rowntree, University of York, Heslington, York YO10 5DD, UK.

Received: 13 April 2018 Accepted: 22 October 2018 Published online: 13 November 2018

\section{References}

1. US Surgeon General. The health consequences of involuntary exposure to tobacco smoke. In: Report of Surgeon general. Atlanta: US DHHS; 2006.

2. Royal College of Physicians. Passive smoking and children. In: A report by the tobacco advisory group. London: RCP. p. 2010.
3. Burke H, Leonardi-Bee J, Hashim A, Pine-Abata H, Chen Y, Cook DG, Britton IR, McKeever TM. Prenatal and passive smoke exposure and incidence of asthma and wheeze: systematic review and meta-analysis. Pediatrics. 2012; 129(4):735-44.

4. Jones LL, Hashim A, McKeever T, Cook DG, Britton J, Leonardi-Bee J. Parental and household smoking and the increased risk of bronchitis, bronchiolitis and other lower respiratory infections in infancy: systematic review and meta-analysis. Respir Res. 2011;12:5.

5. Jones LL, Hassanien A, Cook DG, Britton J, Leonardi-Bee J. Parental smoking and the risk of middle ear disease in children: a systematic review and meta-analysis. Arch Pediatr Adolesc Med. 2012;166(1):18-27.

6. Oberg M, Jaakkola MS, Woodward A, Peruga A, Prüss-Ustün A. Worldwide burden of disease from exposure to second-hand smoke: a retrospective analysis of data from 192 countries. Lancet. 2011;377:139-46.

7. Action on Smoking and Health (ASH).ASH Fact Sheet on secondhand smoke. ASH Fact Sheet. 2014. http://ash.org.uk/information-and-resources/ secondhand-smoke/secondhand-smoke/ (2014). Accessed 17 Mar 2016.

8. Hiscock R, Bauld L, Amos A, Fidler JA, Munafò M. Socioeconomic status and smoking: a review. Ann N Y Acad Sci. 2012;1248:107-23.

9. Geller AC, Rees WW, Brooks DR. The proposal for smoke-free public housing: benefits, challenges, and opportunities for 2 million residents. JAMA. 2016; 315(11):1105-6.

10. Mackenbach JP. The persistence of health inequalities in modern welfare states: the explanation of a paradox. Soc Sci Med. 2012;75(4):761-9.

11. Woolacott NF, Jones L, Forbes CA, Mather LC, Sowden AJ, Song FJ, Raftery JP, Aveyard PN, Hyde CJ, Barton PM. The clinical effectiveness and costeffectiveness of bupropion and nicotine replacement therapy for smoking cessation: a systematic review and economic evaluation. Health Technol Assess. 2002;6(16):1-245.

12. West R, McNeill A, Raw M. Smoking cessation guidelines for health professionals: an update. Health Educ Authority Thorax. 2000;55(12): 987-99.

13. Parrott S, Godfrey C, Raw M, West R, McNeill A. Guidance for commissioners on the cost effectiveness of smoking cessation interventions. Health Educ Authority Thorax. 1998;53(Suppl 5 Pt 2):S1-38.

14. Wang D, Connock M, Barton P, Fry-Smith A, Aveyard P, Moore D. 'Cut down to quit' with nicotine replacement therapies in smoking cessation: a systematic review of effectiveness and economic analysis. Health Technol Assess. 2008;12(2):iii-v ix-xi, 1-135.

15. Office for National Statistics Statistical bulletin: Adult smoking habits in the UK: 2016. 2017. https://www.ons.gov.uk/peoplepopulationandcommunity/ healthandsocialcare/healthandlifeexpectancies/bulletins/ adultsmokinghabitsingreatbritain/2017 (2017). Accessed 17/3/2016.

16. Rosen $L$, Myers $V$, Winickoff J, Kott J. Effectiveness of interventions to reduce tobacco smoke pollution in homes: a systematic review and metaanalysis. Int J Environ Res Public Health. 2015;12(12):16043-59.

17. Ratschen E, Thorley R, Jones L, Opazo Breton M, Cook J, McNeill A, Britton J, Coleman T, Lewis S. A Randomised controlled trial of a complex intervention to reduce children's exposure to secondhand smoke in the home. Tob Control. 2018;27(2):155-62.

18. National Institute for Health and Care Excellence (NICE): guide to the methods of technology appraisal 2013. 2013. https://www.nice.org.uk/ process/pmg9/chapter/foreword (2013). Accessed 17 Mar 2016

19. National Institute for Health and Care Excellence (NICE): Smoking cessation services: Costing template-Implementing NICE guidance. 2008. https://www. nice.org.uk/guidance/PH10 (2008). Accessed 17 Mar 2016.

20. NHS Employers. Agenda for Change pay bands and points from 1 April 2014. http://www.nhsemployers.org/ /media/Employers/Documents/ Pay\%20and\%20reward/AfC\%20pay\%20bands\%20and\%20 points\%20poster\%202014.pdf (2014). Accessed 17 Mar 2016.

21. NHS Employers. Pay Circular (AforC) 3/2008: Pay and conditions for NHS Staff Covered by the Agenda for Change agreement.www.nhsemployers.org (2008). Accessed 17 Mar 2016.

22. Curtis L. Unit Costs of Health and Social Care 2014. Personal Social Services Research Unit. 2014. https://www.pssru.ac.uk/project-pages/unitcosts/unit-costs-2014/ (2014). Accessed 17 Mar 2016.

23. Public Health England (PHE). Unit cost of Smokefree Homes and Cars kit. Email to Charlotte Renwick (charlotte.renwick@york.ac.uk) 201519 Feb.

24. Drummond M, Sculpher M, Claxton K, Stoddart GL, Geroge WT. Methods for the economic evaluation of health care Programmes, Fourth Edition. Oxford: Oxford University Press; 2015. 
25. World Health Organisation (WHO): Health Effects of Particulate Matter: Policy implications for countries in eastern Europe, Caucasus and central Asia Copenhagen; 2013. http://www.euro.who.int/en/health-topics/environmentand-health/air-quality/publications/2013/health-effects-of-particulate-matterpolicy-implications-for-countries-in-eastern-europe,-caucasus-and-centralasia-2013 (2013). Accessed 17 Mar 2016.

26. Drummond MF, Jefferson TO. Guidelines for authors and peer reviewers of economic submissions to the BMJ. The BMJ economic evaluation working party. BMJ. 1996;313(7052):275-83.

27. Coyle D, Davies L, Drummond MF. Trials and tribulations. Emerging issues in designing economic evaluations alongside clinical trials. Int J Technol Assess Health Care. 1998;14(1):135-44.

28. Efron B, Tibshirani R. An introduction to the bootstrap. New York: Chapman \& Hall; 1993.

29. Chaudhary MA, Stearns SC. Estimating confidence intervals for costeffectiveness ratios: an example from a randomized trial. Stat Med. 1996; 15(13):1447-58.

30. Willan AR, O'Brien BJ. Confidence intervals for cost-effectiveness ratios: an application of Fieller's theorem. Health Econ. 1996;5(4):297-305.

31. Severens JL, De Boo TM, Konst EM. Uncertainty of incremental costeffectiveness ratios. A comparison of Fieller and bootstrap confidence intervals. Int J Technol Assess Health Care. 1999:15(3):608-14.

32. Krzyzanowski MC, Cohen A. Update of WHO air quality guidelines. Air Qual Atmos Health. 2008;1:7-13.

33. Dolan P. Modeling valuations for EuroQol health states. Med Care. 1997; 35(11):1095

34. Dolan P, Gudex C, Kind P, Williams A. A social tariff for EuroQol: results from a UK general population survey. In: Discussion paper series (No 138). York: Centre for Health Economics; 1995. https://ideas.repec.org/p/chy/respap/ 138chedp.html (1995). Accessed 17 Mar 2016.

35. Richardson G, Manca A. Calculation of quality adjusted life years in the published literature: a review of methodology and transparency. Health Econ. 2004;13(12):1203-10.

36. Knapp M, Mangalore R. The trouble with QALYs. Epidemiol Psichiatr Soc 2007:16(4):289-93

37. Bauld L, Bell K, McCullough L, Richardson L, Greaves L. The effectiveness of NHS smoking cessation services: a systematic review. J Public Health. 2010;32(1):71-82.

38. Britton J. ABC Of smoking cessation. Malden, Mass: BMJ books; 2004

39. Chaiton M, Diemert L, Cohen JE, Bondy SJ, Selby P, Philipneri A, Schwartz R. Estimating the number of quit attempts it takes to quit smoking successfully in a longitudinal cohort of smokers. BMJ Open. 2016;6(6): e011045.

Ready to submit your research? Choose BMC and benefit from:

- fast, convenient online submission

- thorough peer review by experienced researchers in your field

- rapid publication on acceptance

- support for research data, including large and complex data types

- gold Open Access which fosters wider collaboration and increased citations

- maximum visibility for your research: over $100 \mathrm{M}$ website views per year

At $\mathrm{BMC}$, research is always in progress.

Learn more biomedcentral.com/submissions 